\title{
Tubastraea coccinea: A Non-Indigenous Coral (Cnidaria, Scleractinia) Collected at Arvoredo Island, South of Brazil with Potential MRSA and VRE Antimicrobial Activity
}

\author{
Éverson Miguel Bianco ${ }^{1,2^{*}}$, Simone Quintana de Oliveira ${ }^{2 *}$, Tatiana da Rosa Guimarães ${ }^{2 *}$, \\ Luiza Gabriela de Souza Pessoa' ${ }^{2}$, Maria Eduarda Alves Santos ${ }^{3}$, Felipe Dal-Pizzol ${ }^{4}$, \\ Eloir Paulo Schenkel2 ${ }^{2}$, Flávio Henrique Reginatto# \\ ${ }^{1}$ Departamento de Ciências do Mar, Universidade Federal de São Paulo, Campus Baixada Santista, Santos, \\ Brazil \\ ${ }^{2}$ Programa de Pós-Graduação em Farmácia, Universidade Federal de Santa Catarina, Florianópolis, Brazil \\ ${ }^{3}$ Molecular Invertebrate and Systematics Ecology Laboratory, Department of Biology, Chemistry and Marine \\ Sciences, University of the Ryukyus, Nishihara, Japan \\ ${ }^{4}$ Departamento de Clínica Médica, Universidade Federal de Santa Catarina, Campus Universitário Trindade, \\ Florianópolis, Brazil \\ Email: "flavio.reginatto@ufsc.br
}

Received 11 March 2016; accepted 23 April 2016; published 26 April 2016

Copyright $@ 2016$ by authors and Scientific Research Publishing Inc.

This work is licensed under the Creative Commons Attribution International License (CC BY).

http://creativecommons.org/licenses/by/4.0/

(c) (i) 0pen Access

\section{Abstract}

Bacterial infection is considered to be one of the most critical health issues of the world. It is essential to overcome this problem by the development of new drugs. Marine organisms as corals, sponges, seaweeds, and other are an incredible source of novel pharmacologically active compounds. Herein, the antimicrobial activity (extract/fractions) of the invasive stony coral Tubastraea coccinea was evaluated by the disk diffusion method against 21 microbial strains (ATCC and clinical strains). Micro broth dilution was used to determinate the MIC of the fractions that showed antimicrobial activity by the disk diffusion method. Bioautography assay was also performed. Our results showed that the $n$-butanol (BF) and aqueous fractions (AF) showed activity against ATCC strains Staphylococcus aureus (MIC 31.25 and $250 \mu \mathrm{g} / \mathrm{mL}$ ), Salmonella typhimurium (MIC 125 and $500 \mu \mathrm{g} / \mathrm{mL}$ ), Escherichia coli (MIC 62.5 and $500 \mu \mathrm{g} / \mathrm{mL}$ ) and Pseudomonas aeruginosa (MIC 62.5

\footnotetext{
${ }^{*}$ These authors contributed equally to this work.

"Corresponding author.
}

How to cite this paper: Bianco, É.M., et al. (2016) Tubastraea coccinea: A Non-Indigenous Coral (Cnidaria, Scleractinia) Collected at Arvoredo Island, South of Brazil with Potential MRSA and VRE Antimicrobial Activity. Open Journal of Marine Science, 6, 334-340. http://dx.doi.org/10.4236/ojms.2016.62028 
and $500 \mu \mathrm{g} / \mathrm{mL}$ ), respectively. Moreover, BF fraction was also effective against the clinical strains $S$. aureus (MIC $62.5 \mu \mathrm{g} / \mathrm{mL}$ ), Klebsiella pneumoniae Carbapenemase-KPC (MIC $125 \mu \mathrm{g} / \mathrm{mL}$ ), Methicillin-Resistant Staphylococcus aureus-MRSA (MIC $125 \mu \mathrm{g} / \mathrm{mL}$ ) and Vancomycin-Resistant Enterococcus faecalis - VRE (MIC $62.5 \mu \mathrm{g} / \mathrm{mL}$ ). The ratio MBC/MIC reinforces the bactericidal profile of $\mathrm{BF}$ fraction. The bioautography assay of BF fraction showed the presence of antimicrobial components at $R_{\mathrm{f}} \mathbf{0 . 5 5}$.

\section{Keywords}

Marine Natural Products, Tubastraea coccinea, Scleractinia, Antimicrobial Activity, MethicillinResistant Staphylococcus aureus (MRSA), Vancomycin-Resistant Enterococcus faecalis (VRE)

\section{Introduction}

The increasing global resistance of pathogenic bacteria has become a public health problem and, in attempts to overcome it, research efforts are now addressing the discovery of novel and efficient antibacterial compounds [1]. Furthermore, the emergence of multidrug-resistant bacteria has created a situation in which there are few or no treatment options for infections with certain microorganisms [2]. In this context, unusual sources, such as natural products from marine organisms, are important for antibacterial drug discovery, since they represent a high potential source of new drugs with diverse and often unique structures [3]-[6].

Corals (phylum Cnidaria) represent a dominant group of benthic marine invertebrates that inhabit all oceans, including Brazilian waters. These organisms are of the great interest to the scientific community, since they are source of marine natural products that possess high potential in terms of chemical novelty and as drug leads, yielding structures with novel modes of action [7]-[9].

Tubastraea coccinea Lesson, 1829 (Dendrophylliidae) is a yellow-orange non-indigenous coral found in some regions of Brazil [10], probably first introduced to the Brazilian coast by oil platforms and ships by fouling [11]. A recent report suggests that $T$. coccinea produces chemical defenses by competing against native octocorals [10], and a few data in relation to its ecological significance [12], chemical composition [13] as well as pharmacological properties are reported.

Thus, the aim of this work was to evaluate the antimicrobial potential of extract and related fractions (HF, BF and AF) from the invasive stony coral T. coccinea, against several microorganism strains as well as multi-drug resistant bacteria by the disk diffusion, microdilution assay and by bioautography.

\section{Material and Methods}

\subsection{Collection and Extractions}

Coral collection and extraction: Specimens of T. coccinea were collected by SCUBA at Arvoredo Island, in the state of Santa Catarina, Brazil, at depths of 3 to $10 \mathrm{~m}$, in February 2012. The coral material was manually cleaned to remove associated organisms, and immediately frozen and kept at $-20^{\circ} \mathrm{C}$ until processed. A voucher specimen (CC UFSC 0351) was deposited at the invertebrate collection of the Department of Ecology and Zoology of Universidade Federal de Santa Catarina. The material (160 g, wet weight) was blended in EtOH $92 \%$ (7 days), filtered and dried under reduced pressure, providing the ethanol crude extract (ECE). The ECE was partitioned with $n$-hexane $/ \mathrm{H}_{2} \mathrm{O}$ and $n$ - $\mathrm{BuOH} / \mathrm{H}_{2} \mathrm{O}$, yielding the $n$-hexane $(\mathrm{HF}), n$-butanol $(\mathrm{BF})$ and the aqueous residue (ARF) fractions, respectively. Then, ARF was submitted to XAD-4, yielding the AF (aqueous fraction).

\subsection{Microorganism Strains}

Twenty one microbial species were analyzed, including 14 ATCC strains [Candida albicans (ATCC 10231); Candida tropicalis (ATCC 13803); Clostridium sporogenes (ATCC 11437); Enterobacter cloacae (ATCC 13047); Enterococcus faecalis (ATCC 29212); Escherichia coli (ATCC 25922); Klebsiella pneumoniae (ATCC 13883); Pseudomonas aeruginosa (ATCC 27853); Salmonella typhimurium (ATCC 14028); Shigella flexneri (ATCC 12022); Staphylococcus aureus (ATCC 25923); Staphylococcus epidermidis (ATCC 12228); Strepto- 
coccus pneumoniae (ATCC 49619); Streptococcus pyogenes (ATCC 19615)], and 7 clinical strains isolated from patients in São José Hospital, Criciúma city/Brazil [Acinetobacter baumannii, Enterococcus faecium, Klebsiella pneumoniae, Klebsiella pneumoniae carbapenemase (KPC), Staphylococcus aureus, Methicillinresistant Staphylococcus aureus (MRSA) and Vancomycin-resistant Enterococcus faecalis (VRE)].

\subsection{Disk Diffusion Method}

The antimicrobial activities were evaluated by the disk diffusion method, as previously described by De Oliveira et al. [14] with minor modifications. Standard antibiotic disks were selected according to the sensitivity of the microorganism tested. Thus, ampicillin (10 $\mu \mathrm{g})$, ceftazidime (30 $\mu \mathrm{g})$, chloramphenicol (30 $\mu \mathrm{g})$, doxycycline (30 $\mu \mathrm{g})$, fluconazole $(25 \mu \mathrm{g})$, imipenem (10 $\mu \mathrm{g})$, levofloxacin $(5 \mu \mathrm{g})$, oxacilline $(1 \mu \mathrm{g})$, polymyxin b (300 $\mu \mathrm{g})$ and vancomycin (30 $\mu \mathrm{g})$ were used [15].

\subsection{Determination of the Clinical Strains Sensitivity to Antibiotics}

Antibiotic sensitivity testing of the clinical isolates was performed using disc diffusion method [16]. Antibacterial agents of different classes were used, including amikacin; ampicillin; ampicillin/sulbactam; ciprofloxacin; levofloxacin; cephepime; chloramphenicol; erytromycin; gentamicin; imipenem; oxacillin; piperacillin/tazobactam; sulphazotrim; vancomycin and clindamycin.

\subsection{Micro Broth Dilution}

The microdilution assay was performed according to the CLSI guidelines [16]. Briefly, each well of a 96-well microplate was coated with $100 \mu \mathrm{L}$ of Muller Hinton broth together $100 \mu \mathrm{L}$ of active fractions in serial dilutions (2000 $\mu \mathrm{g} / \mathrm{mL}-3.9 \mu \mathrm{g} / \mathrm{mL}$ ). After $5 \mu \mathrm{L}$ suspension, the test strain (equivalent to $0.5 \mathrm{McFarland}$ standard) was replaced into wells. The microplates were incubated at $35^{\circ} \mathrm{C}$ for $18 \mathrm{~h}$ and the MIC was defined as the lowest concentration of fractions in which the microorganism tested did not show visible growth. The MBC was performed on nutrient agar plates, and was defined as the lowest concentration that showed negative growth.

\subsection{Bioautography}

Thin-layer chromatography (TLC) plates $(10 \times 10 \mathrm{~cm})$ were loaded with $20 \mu \mathrm{L}$ of the extract (BF) solutions at a concentration of $100 \mathrm{mg} / \mathrm{mL}$. The plates were developed using $n-\mathrm{BuOH} / \mathrm{AcOH} / \mathrm{H}_{2} \mathrm{O}(6: 2: 1)$ as mobile phase. After the solvent had evaporated from the TLC plates $(24 \mathrm{~h})$, Muller Hinton agar (HIMEDIA ${ }^{\circledR}$ ) was deposited over the plates, and after solidification, a microorganism suspension at $1.5 \times 10^{8} \mathrm{CFU} / \mathrm{mL}$ was added over the culture medium. The plates were incubated at $35^{\circ} \mathrm{C} \pm 1^{\circ} \mathrm{C}$, and after $18 \mathrm{~h}$, the bioautogram was sprayed with an aqueous solution of 2,3,5-triphenyltetrazolium chloride (TTC) (Vetec ${ }^{\circledR}$ ) and incubated at $35^{\circ} \mathrm{C} \pm 1{ }^{\circ} \mathrm{C}$ for $4 \mathrm{~h}$. Inhibition zones indicated the presence of bioactive compounds [15] [17].

\section{Results and Discussion}

Among the fractions assayed, BF and AF showed moderate activity against ATCC strains of S. aureus (10.5 mm and $9 \mathrm{~mm}$ of inhibition zones, respectively), and weak activity against $S$. typhimurium ( $8 \mathrm{~mm}$ and $8 \mathrm{~mm})$, E. coli ( $8.5 \mathrm{~mm}$ and $7.5 \mathrm{~mm}$ ), and P. aeruginosa $(7 \mathrm{~mm}$ and $7 \mathrm{~mm}$ ). The HF fraction did not show activity against all bacteria or fungi assayed. Concerning the clinical strains, only BF fraction showed moderate activity against $S$. aureus $(12 \mathrm{~mm})$, KPC (11 mm), MRSA (10 mm) and VRE (10 mm) (Table 1).

The fractions that showed antibacterial activity by the disk diffusion method were further tested by the microplate assay, to determine the minimum inhibitory concentration (MIC). In addition, the wells that showed negative visible growth after $18 \mathrm{~h}$ of incubation were replated on agar nutrient plates, to obtain the minimum bactericidal concentration (MBC) of the fractions. The MIC values of the BF and AF fractions were, respectively: 31.25 and $250 \mu \mathrm{g} / \mathrm{mL}$ (S. aureus), 125 and $500 \mu \mathrm{g} / \mathrm{mL}$ (S. typhimurium), 62.5 and $500 \mu \mathrm{g} / \mathrm{mL}$ (E. coli), and 62.5 and $500 \mu \mathrm{g} / \mathrm{mL}$ (P. aeruginosa) (Table 2). On the other hand, BF and AF fractions showed MBC values 62.5 and $500 \mu \mathrm{g} / \mathrm{mL}$ (S. aureus), 250 and $1000 \mu \mathrm{g} / \mathrm{mL}$ (S. typhimurium), 125 and $1000 \mu \mathrm{g} / \mathrm{mL}$ (E. coli), and 125 and $1000 \mu \mathrm{g} / \mathrm{mL}$ (P. aeruginosa).

It is important to emphasize that the BF fraction showed activity against $P$. aeruginosa, which has, in clinical cases, a high degree of resistant against multiple classes of antibiotics [18]. Moreover, in contrast to the weak 
Table 1. Antibacterial and antifungal activity of fractions of the coral Tubastraea coccinea by the disk diffusion method.

\begin{tabular}{|c|c|c|c|}
\hline \multirow{2}{*}{ ATCC strains } & \multicolumn{3}{|c|}{ Fractions assayed } \\
\hline & HF & BF & AF \\
\hline Candida albicans (ATCC 10231) & - & - & - \\
\hline Candida tropicalis (ATCC 13803) & - & - & - \\
\hline Clostridium sporogenes (ATCC 11437) & - & - & - \\
\hline Enterobacter cloacae (ATCC 13047) & - & - & - \\
\hline Enterococcus faecalis (ATCC 29212) & - & - & - \\
\hline Escherichia coli (ATCC 25922) & - & + & + \\
\hline Klebsiella pneumoniae (ATCC 13883) & - & - & - \\
\hline Pseudomonas aeruginosa (ATCC 27853) & - & + & + \\
\hline Salmonella typhimurium (ATCC 14028) & - & + & + \\
\hline Shigella flexneri (ATCC 12022) & - & - & - \\
\hline Staphylococcus aureus (ATCC 25923) & - & ++ & ++ \\
\hline Staphylococcus epidermidis (ATCC 12228) & - & - & - \\
\hline Streptococcus pneumoniae (ATCC 49619) & - & - & - \\
\hline Streptococcus pyogenes (ATCC 19615) & - & - & - \\
\hline Clinical strains & HF & BF & $\mathbf{A F}$ \\
\hline Acinetobacter baumannii & - & - & - \\
\hline Enterococcus faecium & - & - & - \\
\hline Klebsiella pneumoniae & - & - & - \\
\hline KPC & - & ++ & - \\
\hline Staphylococcus aureus & - & ++ & - \\
\hline MRSA & - & ++ & - \\
\hline VRE & - & ++ & - \\
\hline
\end{tabular}

(-): not active; (+): 7 - $8.5 \mathrm{~mm}$; (++): 9 - $12 \mathrm{~mm}$; (+++): 13 - $16 \mathrm{~mm}$; (++++): 17 - $20 \mathrm{~mm}$. Positive controls: for ATCC strains were used ampicillin $(10 \mu \mathrm{g})$, ceftazidime $(30 \mu \mathrm{g})$, chloramphenicol $(30 \mu \mathrm{g})$, doxycycline $(30 \mu \mathrm{g})$, fluconazole $(25 \mu \mathrm{g})$ and oxacilline $(1 \mu \mathrm{g})$; for clinical strains were used imipenem $(10 \mu \mathrm{g})$, levofloxacin $(5 \mu \mathrm{g})$, oxacilline $(1 \mu \mathrm{g})$, polymyxin b $(300 \mu \mathrm{g})$ and vancomycin $(30 \mu \mathrm{g})$. HF: $n$-hexane fraction; BF: $n$-BuOH fraction; AF: aqueous fraction; KPC: Klebsiella pneumoniae carbapenemase; MRSA: Methicillin-resistant Staphylococcus aureus; VRE: Vancomycin-resistant Enterococcus faecalis.

Table 2. Results of MIC $(\mu \mathrm{g} / \mathrm{mL}), \mathrm{MBC}(\mu \mathrm{g} / \mathrm{mL})$ and MBC/MIC ratio of BF fraction of the coral Tubastrea coccinea.

\begin{tabular}{cccc}
\hline \multirow{2}{*}{ ATCC strains } & \multicolumn{3}{c}{ BF fraction } \\
\cline { 2 - 4 } Escherichia coli (ATCC 25922) & MIC $(\boldsymbol{\mu g} / \mathbf{m L})$ & MBC $(\boldsymbol{\mu g} / \mathbf{m L})$ & MBC/MIC \\
\hline Pseudomonas aeruginosa (ATCC 27853) & 62.5 & 125 & 2 \\
Salmonella typhimurium (ATCC 14028) & 62.5 & 125 & 2 \\
Staphylococcus aureus (ATCC 25923) & 125 & 250 & 2 \\
\hline Clinical strains & 31.25 & 62.5 & MBC/MIC \\
\hline Staphylococcus aureus & MIC $(\boldsymbol{\mu g} / \mathbf{m L})$ & $\mathbf{M B C}(\boldsymbol{\mu g} / \mathbf{m L})$ & 12 \\
KPC & 62.5 & 125 & 1 \\
MRSA & 125 & 125 & 1 \\
\hline
\end{tabular}

Samples with MIC > $1000 \mu \mathrm{g} / \mathrm{mL}$ were considered inactive; MIC from $500-1000 \mu \mathrm{g} / \mathrm{mL}$ antibacterial activity was considered weak; MIC from 100 to $500 \mu \mathrm{g} / \mathrm{mL}$ the antibacterial activity was considered moderate; MIC is equal or smaller than $100 \mu \mathrm{g} / \mathrm{mL}$, the antibacterial activity was considered significant. KPC: Klebsiella pneumoniae carbapenemase; MRSA: Methicillin-resistant Staphylococcus aureus; VRE: Vancomycin-resistant Enterococcus faecalis. 
activity detected by the disk diffusion assay, the MIC of the BF fraction against $P$. aeruginosa, was higher when compared among all the samples tested $(62.5 \mu \mathrm{g} / \mathrm{mL})$, except against $S$. aureus, which showed MIC 31.25 $\mu \mathrm{g} / \mathrm{mL}$.

The BF fraction also exhibited significant growth inhibitory activities against the four clinical strains with MICs ranging from 62.5 to $125 \mu \mathrm{g} / \mathrm{mL}$. Further, this fraction showed the same value of MBC $(125 \mu \mathrm{g} / \mathrm{mL})$ against $S$. aureus, KPC and MRSA. The VRE was susceptible to BF fraction with MBC of $62.5 \mu \mathrm{g} / \mathrm{mL}$ (Table 2).

The minimum bactericidal concentrations (MBC) for each sample were compared with the MIC values. Low $\mathrm{MBC} / \mathrm{MIC}$ ratios $(\leq 4)$ demonstrate bactericidal activity, while ratios higher than four indicate the bacteriostatic mode of action [19]. Our results reinforce the bactericidal activity detected for BF fraction in the MBC assay for the all strains available (Table 2).

These findings demonstrated that the BF fraction has a higher potential antimicrobial activity, including clinical multi resistant strains, suggesting that this activity should be higher when the compounds responsible for the activity are isolated.

In addition, the most active fraction (BF) was submitted to the bioautography assay for S. aureus, S. typhimurium, E. coli, P. aeruginosa and four clinical strains (S. aureus, KPC, MRSA and VRE). In all bioautography analyses, the inhibition zone of the bioactive compounds was detected at Rf. 0.55 [TLC developed with $n$-BuOH/ $\mathrm{AcOH} / \mathrm{H}_{2} \mathrm{O}$ (6:2:1)] (data not shown). Since the bioactive compound showed inhibition zone at Rf. 0.55, we decide to develop a TLC chemical characterization of this compound using the same chromatographic conditions. The TLC fingerprint of the bioactive fraction showed the presence of compounds with alkaloids profile after Dragendorff nebulization (data not shown). This result is in agreement to literature data that reports stony scleratinian corals, Tubastraea (Dendrophylliidae) genus as a source of biologically active alkaloid derivatives including aplysinopsin and (bis)-indole alkaloids [20]-[23].

Regarding the pharmacological properties of this coral genus, there is only one report of antimicrobial activity from methanol extract of Tubastraea faulkneri, against Vibrio alginolyticus, Vibrio harveyi, Photobacterium damselae, Alteromonas rubra, Staphylococcus aureus and Synechococcus sp. [24]. Additionally, from the same species, aplysinopsin, 6-bromoaplysinopsin, 6-bromo-29-de-N-methylaplysinopsin and its dimer have also been reported [25]-[27]. Moreover, Zoraghi and colleagues [28], reported that MRSA pyruvate kinase is a potential target for (bis)-indole alkaloids with antibacterial activity.

\section{Conclusion}

In this work we described the antimicrobial potential of the extract and fractions obtained from Scleractinia coral $T$. coccinea. Our results showed that the $n$-butanol fraction (BF fraction) was effective against Gram-positive and Gram-negative bacterial, including multi-resistant clinical strains. Moreover, it is relevant to emphasize the importance of marine biodiversity as sources of secondary metabolites with potential pharmacological activities, which could be used on development of new drugs and/or as lead compound. Further studies are in progress in our laboratory, to isolate these bioactive compounds.

\section{Acknowledgements}

The authors would like to thank CNPq (Conselho Nacional de Desenvolvimento Científico e Tecnológico, Brazil), CAPES (Coordenação de Aperfeiçoamento de Pessoal de Nível Superior) and FAPESC (Fundação de Amparo à Pesquisa e Inovação do Estado de Santa Catarina) for their financial support and their research fellowships. Hence, we are grateful to clinical laboratory of São José Hospital (Criciúma city/Brazil) for furnished clinical bacterial strains.

\section{Conflicts of Interest}

The authors declare no conflict of interest.

\section{References}

[1] Devasahayam, G., Scheld, W.M. and Hoffman, P.S. (2010) Newer Antibacterial Drugs for a New Century. Expert Opinion on Investigational Drugs, 19, 215-234. http://dx.doi.org/10.1517/13543780903505092 
[2] Spellberg, B., Powers, J.H., Brass, E.P., Miller, L.G. and Edwards-Jr., J.E. (2004) Trends in Antimicrobial Drug Development: Implications for the Future. Clinical Infectious Diseases, 38, 1279-1286. http://dx.doi.org/10.1086/420937

[3] Fusetani, N. (2000) Drugs from the Sea. S. Karger AG, Basel, 158 p. http://dx.doi.org/10.1159/isbn.978-3-318-00599-8

[4] Abad, M.J., Bedoya, L.M. and Bermejo, P. (2011) Marine Compounds and Their Antimicrobial Activities. In: MéndezVilas, A., Ed., Science against Microbial Pathogens: Communicating Current Research and Technological Advances, FORMATEX, Badajoz, 1293-1306.

[5] Costa-Lotufo, L.V., Wilke, D.V., Jimenez, P.C. and Epifanio, R.A. (2009) Organismos marinhos como fonte de novos fármacos: Histórico \& perspectivas. Química Nova, 32, 703-716. http://dx.doi.org/10.1590/S0100-40422009000300014

[6] Molinski, T.F., Dalisay, D.S., Lievens, S.L. and Saludes, J.P. (2009) Drug Development from Marine Natural Products. Nature Reviews Drug Discovery, 8, 69-85. http://dx.doi.org/10.1038/nrd2487

[7] Wang, C.Y., Liu, H.Y., Shao, C.L., Wang, Y.N., Li, L. and Guan, H.S. (2008) Chemical Defensive Substances of Soft Corals and Gorgonians. Acta Ecologica Sinica, 28, 2320-2328. http://dx.doi.org/10.1016/S1872-2032(08)60048-7

[8] Jha, R.K. and Xu, Z.-R. (2004) Biomedical Compounds from Marine Organisms. Marine Drugs, 2, 123-146. http://dx.doi.org/10.3390/md203123

[9] Rocha, J., Peixe, L., Gomes, N.C.M. and Calado, R. (2011) Cnidarians as a Source of New Marine Bioactive Compounds-An Overview of the Last Decade and Future Steps for Bioprospecting. Marine Drugs, 9, 1860-1886. http://dx.doi.org/10.3390/md9101860

[10] Ferreira, C.E.L. (2003) Non-Indigenous Corals at Marginal Sites. Coral Reefs, 22, 498. http://dx.doi.org/10.1007/s00338-003-0328-z

[11] De Paula, A.F. and Creed, J.C. (2004) Two Species of the Coral Tubastraea (Cnidaria, Scleractinia) in Brazil: A Case of Accidental Introduction. Bulletin of Marine Science, 74, 175-183.

[12] Lages, B.G., Fleury, B.G., Pinto, A.C. and Creed, J.C. (2010) Chemical Defenses against Generalist Fish Predators and Fouling Organisms in Two Invasive Ahermatypic Corals in the Genus Tubastraea. Marine Ecology, 31, 473-482. http://dx.doi.org/10.1111/j.1439-0485.2010.00376.x

[13] Lages, B.G., Fleury, B.G., Rezende, C.M., Pinto, A.C. and Creed, J.C. (2010) Chemical Composition and Release in Situ Due to Injury of the Invasive Coral Tubastraea (Cnidaria, Scleractinia). Brazilian Journal of Oceanography, 58, 47-56.

[14] De Oliveira, S.Q., Trentin, V.H., Kappel, V.D., Barelli, C., Gosmann, G. and Reginatto, F.H. (2005) Screening of Antibacterial Activity of South Brazilian Baccharis Species. Pharmaceutical Biology, 43, 434-438. http://dx.doi.org/10.1080/13880200590963754

[15] Kappel, V.D., Costa, G.M., Scola, G., Silva, F.A., Landell, M.F., Valente, P., Souza, D.G., Vanz, D.C., Reginatto, F.H. and Moreira, J.C.F. (2008) Phenolic Content and Antioxidant and Antimicrobial Properties of Fruits of Capsicum baccatum L. var. pendulum at Different Maturity Stages. Journal of Medicinal Food, 11, 267-274. http://dx.doi.org/10.1089/jmf.2007.626

[16] Clinical and Laboratory Standards Institute (2002) Performance Standards for Antimicrobial Disk Susceptibility Tests: Approved Standard M2-A8. In: Performance Standards for Antimicrobial Susceptibility Testing, 8th Edition, Clinical and Laboratory Standards Institute, Wayne, 1-58.

[17] Choma, I.M. and Grzelak, M. (2011) Bioautography Detection in Thin-Layer Chromatography. Journal of Chromatography A, 1218, 2684-2691. http://dx.doi.org/10.1016/j.chroma.2010.12.069

[18] Sun, H.Y., Shields, R.K., Cacciarelli, T.V., Muder, R.R. and Singh, N. (2010) A Novel Combination Regimen for the Treatment of Refractory Bacteremia Due to Multidrug Resistant Pseudomonas aeruginosa in a Liver Transplant Recipient. Transplant Infectious Disease, 12, 555-560. http://dx.doi.org/10.1111/j.1399-3062.2010.00543.x

[19] Olech, M., Nowak, R., Nowacka, N., Pecio, L., Oleszek, W., Los, R., Malm, A. and Rzymowska, J. (2015) Evaluation of Rose Roots, a Post-Harvest Plantation Residue as a Source of Phytochemicals with Radical Scavenging, Cytotoxic, and Antimicrobial Activity. Industrial Crops and Products, 69, 129-136. http://dx.doi.org/10.1016/j.indcrop.2015.02.017

[20] Bialonska, D. and Zjawiony, J.K. (2009) Aplysinopsins-Marine Indole Alkaloids: Chemistry, Bioactivity and Ecological Significance. Marine Drugs, 7, 166-183. http://dx.doi.org/10.3390/md7020166

[21] Fusetani, N., Asano, M., Matsunaga, S. and Hashimoto, K. (1986) Bioactive Marine Metabolites. XV. Isolation of Aplysinopsin from the Scleractinian Coral Tubastrea aurea as an Inhibitor of Development of Fertilized Sea Urchin Eggs. Comparative Biochemistry and Physiology Part B: Biochemistry and Molecular Biology, 85, 845-846. http://dx.doi.org/10.1016/0305-0491(86)90184-7

[22] Iwagawa, T., Miyazaki, M., Okumara, H., Nakatani, M., Doe, M. and Takemura, K. (2003) Three Novel Bis(Indole) 
Alkaloids from a Stony Coral Tubastrea sp. Tetrahedron Letters, 44, 2533-2535. http://dx.doi.org/10.1016/S0040-4039(03)00331-9

[23] Iwagawa, T., Miyazaki, M., Yokogawa, Y., Okamura, H., Nakatani, M., Doe, M., Morimoto, Y. and Takemura, K. (2008) Aplysinopsin Dimmers from a Stony Coral Tubastrea aurea. Heterocycles, 75, 2023-2028. http://dx.doi.org/10.3987/COM-08-11358

[24] Koh, E.G.L. (1997) Do Scleractinian Corals Engage in Chemical Warfare against Marine Microbes? Journal of Chemical Ecology, 23, 379-398. http://dx.doi.org/10.1023/B:JOEC.0000006366.58633.f4

[25] Koh, E.G.L. and Sweatmanb, H. (2000) Chemical Warfare among Scleractinians: Bioactive Natural Products from Tubastraea faulkneri Wells Kill Larvae of Potential Competitors. Journal of Experimental Marine Biology and Ecology, 251, 141-160. http://dx.doi.org/10.1016/S0022-0981(00)00222-7

[26] Zhang, W., Gavagnin, M., Guo, Y.W., Huang, T.Z. and Wang, J.J. (2006) Chemical Studies on the South China Sea Stony Coral Tubastraea sp. Chinese Journal of Natural Medicines, 4, 94-97.

[27] Meyer, M., Delberghe, F., Liron, F., Guillaume, M., Valentin, A. and Guyot, M. (2009) An Antiplasmodial New (Bis)Indole Alkaloid from the Hard Coral Tubastraea sp. Natural Product Research, 23, 178-182. http://dx.doi.org/10.1080/14786410801925134

[28] Zoraghi, R., Worrall, L., See, R.H., Strangman, W., Popplewell, W.L., Gong, H., Samaai, T., Swayze, R.D., Kaur, S., Vuckovic, M.B., Finlay, B.B., Brunham, R.C., McMaster, W.R., Davies-Coleman, M.T., Strynadka, N.C., Andersen, R.J. and Reiner, N.E. (2011) Methicillin-Resistant Staphylococcus aureus (MRSA) Pyruvate Kinase as a Target for Bis-Indole Alkaloids with Antibacterial Activities. The Journal of Biological Chemistry, 286, 44716-44725. http://dx.doi.org/10.1074/jbc.M111.289033 